\title{
Factors affecting fungus-induced larval mortality in Anopheles gambiae and Anopheles stephensi
}

\author{
Tullu Bukhari ${ }^{1}$, Anthonieke Middelman ${ }^{1}$, Constantianus JM Koenraadt ${ }^{1}$, Willem Takken ${ }^{1}$, Bart GJ Knols
}

\begin{abstract}
Background: Entomopathogenic fungi have shown great potential for the control of adult malaria vectors. However, their ability to control aquatic stages of anopheline vectors remains largely unexplored. Therefore, how larval characteristics (Anopheles species, age and larval density), fungus (species and concentration) and environmental effects (exposure duration and food availability) influence larval mortality caused by fungus, was studied.

Methods: Laboratory bioassays were performed on the larval stages of Anopheles gambiae and Anopheles stephensi with spores of two fungus species, Metarhizium anisopliae and Beauveria bassiana. For various larval and fungal characteristics and environmental effects the time to death was determined and survival curves established. These curves were compared by Kaplan Meier and Cox regression analyses.

Results: Beauveria bassiana and Metarhizium anisopliae caused high mortality of An. gambiae and An. stephensi larvae. However, Beauveria bassiana was less effective (Hazard ratio $(H R)<1$ ) compared to Metarhizium anisopliae. Anopheles stephensi and An. gambiae were equally susceptible to each fungus. Older larvae were less likely to die than young larvae $(H R<1)$. The effect of increase in fungus concentration on larval mortality was influenced by spore clumping. One day exposure to fungal spores was found to be equally effective as seven days exposure. In different exposure time treatments $0-4.9 \%$ of the total larvae, exposed to fungus, showed infection at either the pupal or adult stage. Mortality rate increased with increasing larval density and amount of available food.

Conclusions: This study shows that both fungus species have potential to kill mosquitoes in the larval stage, and that mortality rate depends on fungus species itself, larval stage targeted, larval density and amount of nutrients available to the larvae. Increasing the concentration of fungal spores or reducing the exposure time to spores did not show a proportional increase and decrease in mortality rate, respectively, because the spores clumped together. As a result spores did not provide uniform coverage over space and time. It is, therefore, necessary to develop a formulation that allows the spores to spread over the water surface. Apart from formulation appropriate delivery methods are also necessary to avoid exposing non-target organisms to fungus.
\end{abstract}

\section{Background}

Over the last decade, the potential of larval control has been increasingly recognized in the realm of integrated malaria control programmes [1-4]. Larval control can be economical and effective when applied with a good understanding of local disease determinants and vector ecology [5-7]. In urban areas, the breeding sites of mosquitoes are well defined and accessible, making it easier to target them. As a result larval control can steadily support other intervention methods like indoor residual spraying (IRS)

\footnotetext{
* Correspondence: bart@malariaworld.org

${ }^{2}$ Division of Infectious Diseases, Tropical Medicine \& AIDS, Academic Medical
} Center, University of Amsterdam, the Netherlands and/or insecticide-treated bed nets (ITNs) [8]. Increasing urbanization thus underscores the need to develop larval control methods $[7,9,10]$. In this perspective, Bacillus thuringiensis var. israelensis (Bti) and B. sphaericus (Bs) have been applied on a large scale in urban settings and provided promising results $[8,11]$. In general, there is relatively little chance of resistance developing against these biological control agents as compared to chemical-based interventions like IRS and ITNs although it cannot be ruled out completely. For instance, the development of resistance against $B s$ in Culex spp. was reported within two years of field application $[12,13]$. It is, therefore, worthwhile to investigate other biological control agents 
for their larvicidal properties in order to extend the existing arsenal of larval biopesticides.

The entomopathogenic characteristic of Metarhizium anisopliae was identified more than 125 years ago while that of Beauveria bassiana was noted even earlier, in 1835 [14]. These entomopathogens belong to a group of anamorphic fungi called Hyphomycetes, which reproduce by spores (conidia) [15]. The spores have proven effective against mosquito larvae of the genus Aedes, Culex and Anopheles in the laboratory [16-20]. Studies have been undertaken to increase the virulence of the spores by insect-passaging and to increase the persistence of the spores through formulation [21,22]. Miranpuri and Khachatourians [23] showed that the primary infection sites of the fungal spores in the larval bodies is the head and anal region while fungal development mostly takes place in the larval gut. Apart from the larval stage, eggs (Aedes) treated with $M$. anisopliae and $B$. bassiana show a reduced hatch rate. Ovicidal property of $M$. anisopliae is best expressed at high humidity, which is a normal characteristic of anopheline oviposition sites [24,25]. However, attempts to infect newly emerged adults by dusting spores on vegetation surrounding the breeding sites were unsuccessful under semi-field conditions [17]. Scholte et al [26] infected adult mosquitoes by providing them with a fungus-treated resting site in the form of fungus-treated black cloth attached to ceilings of rural houses in Tanzania [26]. Farenhorst et al showed how water storage pots can serve as a suitable site for delivering a fungal infection to resting adult mosquitoes [27,28].

Use of fungal spores as a larvicide could complement adult control but in areas where the breeding sites are well defined, accessible and are not being used for domestic purposes. A number of factors can influence larval mortality caused by fungus, e.g. species and larval stage of mosquito targeted, besides the species, isolate and amount of the fungus applied. As in field the persistence of the spores can be affected by environmental conditions, mosquitoes may not be exposed to virulent spores for long. Reduced exposure time can also influence the control potential of fungus. Even without a control agent, the amount of nutrients in the breeding sites and larval density is known to have impact on larval survival [29]. Availability of nutrients can also decrease the intake of fungal spores by larvae, as fungal spores mainly enter the larval gut, the main infection site, due to ingestion [30]. These factors can increase or decrease the impact of fungal spores on the larvae. In this laboratory-based study the effect of the above-mentioned factors was evaluated on fungus-induced larval mortality for a better comprehension of its control potential and scope for field application. Two entomopathogenic fungi, $M$. anisopliae and B. bassiana, were tested against An. stephensi and An. gambiae. Anopheles stephensi is the main Asian malaria vector that breeds predominantly in man-made habitats while $A n$. gambiae is an important African malaria vector that breeds in temporary aquatic habitats.

\section{Methods}

\section{Mosquitoes}

Anopheles stephensi (Strain STE 2, MRA no. 128, origin India) and An. gambiae s.s. (Suakoko strain, courtesy of Prof. M. Coluzzi) were reared in climate controlled chambers maintained at a temperature of $27 \pm 1^{\circ} \mathrm{C}$, 12L:12D photoperiod and a relative humidity of $70 \pm 5 \%$. The adults, kept in holding cages $(30 \times 30 \times 30 \mathrm{~cm})$, had ad libitum access to 6\% glucose/water solution. 4-6 Days old females were blood fed on the forearm of a volunteer and provided with oviposition cups, covered with a coneshaped filter paper. The eggs laid on the filter paper were transferred to plastic trays $(25 \times 25 \times 8 \mathrm{~cm})$. Hatched larvae were fed on Liquifry No. 1 (Interpet Ltd., Dorking, Surrey, UK) for the first two days and then on Tetramin ${ }^{\circ}$ for the rest of the larval period. Pupae were collected in small cups and transferred to holding cages.

\section{Fungus spores}

Spores of Metarhizium anisopliae (ICIPE-30) and Beauveria bassiana (IMI- 391510) were provided by the Department of Bioprocess Engineering, Wageningen University and stored in plastic tubes at $4^{\circ} \mathrm{C}$.

\section{Experimental conditions}

All experiments were performed in rooms with climatic conditions similar to the rearing chambers. Tap water was left overnight in the plastic larval trays for dechlorination.

Susceptibility of mosquito species, the effect of fungus species, larval stage and fungus concentration

It was determined whether larvae are more or less likely to be infected with fungal spores depending on their species, development stage, fungus species and spore concentration. This was done by comparing the mortality of early ( $\mathrm{L}_{1-2}, 1-3$ days old) and late $\left(\mathrm{L}_{3-4}, 4-8\right.$ days old) larval stages of $A n$. stephensi and An. gambiae caused by different concentrations of $M$. anisopliae or $B$. bassiana spores. Fifty $\left(\mathrm{L}_{1-2}\right.$ or $\left.\mathrm{L}_{3-4}\right)$ larvae were placed in plastic trays $(25 \times 25 \times 8 \mathrm{~cm})$, filled with 1 litre of dechlorinated water, and fed on Tetramin ${ }^{\bullet}$ (0.1-0.2 mg/ larva/day for $\mathrm{L}_{1-2}$ and $0.3 \mathrm{mg} /$ larva/day for $\mathrm{L}_{3-4}$ ) [31]. In the treatment trays fungal spores were dusted on the water surface $\left(441 \mathrm{~cm}^{2}\right)$ in different amounts i.e. $2.5,5$, 10 or $20 \mathrm{mg}$. Dead larvae and pupae were recorded daily and removed for the next 12 days. The amount of food added was adjusted to the daily mortality and/or pupation. The resulting 40 treatments (two mosquito species $\times$ two developmental stages $\times$ two fungus species $\times$ four fungal concentrations and one control) were each replicated four times. The treatments and the 
replicates were not run in parallel but at different times depending upon the availability of experimental space and mosquito larvae. Every replicate had a control and the four fungus concentrations. The same protocol was followed each time and the same batch of fungi was used for all these experiments.

\section{Effect of exposure time}

The mortality of $\mathrm{L}_{3-4}$ larvae of An. stephensi and An. gambiae when exposed to M. anisopliae or B. bassiana spores for different time periods was compared. Fifty larvae were placed in plastic trays and fed as described above. Out of five trays, four were treated with $10 \mathrm{mg}$ of spores and one was used as control. After one day, the larvae that had not died or pupated, in a fungus-treated tray were transferred by a plastic pipette to a clean water tray, with an intermediate rinsing to reduce the chance of transferring spores. Similar transfers were carried out after 3, 5, and 7 days. The number of larvae that could be transferred on these days was less than 50 because larvae either pupated or died due to fungus infection. The control larvae were also transferred to compensate for any mechanical injury caused by the pipette. The control larvae were transferred to an another tray containing fresh water on day 1 . This day was selected because at that time most of the larvae were still alive. Prior to and after the transfer, the larvae were fed $(0.3 \mathrm{mg} / \mathrm{larva} /$ day $)$ and monitored over 10 days, for death or pupation. All the trays, the untreated and treated water trays in which the larvae were added first, the trays that were used for rinsing the larvae and the trays, into which the larvae were transferred, were all filled with water at the same time. This was to ensure that when a larva was transferred from one tray to another the only difference was the absence of fungus and not fresh acclimatized water. The resulting pupae were kept in a plastic cup for adult emergence. The wing length (right wing, ventral side, from the notch of the alula to the wing tip) of the adults was measured (in $\mathrm{mm}$ ), to the nearest second decimal place, as a proxy for mosquito body size [32]. The 20 treatments (two mosquito species $\times$ two fungal species $\times$ four time periods and one control) were each replicated four times. The pupae and adults that showed fungus infection, apparent due to mycelia growth, were observed under a microscope to identify the fungus species [15]. Fungus species was identified to make sure that the infection was due to $M$. anisopliae or B. bassiana. Similar to the first experiment the replicates and treatments were not carried out in parallel. Every replicate consisted of a control and the four exposure times. The same protocol was used for each replica and treatment. Further the same batch of fungi was used for all the treatments and replicates.

\section{Effect of food quantity}

This experiment was carried out to determine if a lower quantity of food will increase the intake of fungal spores and lead to an increased mortality rate. In separate trays,
$\mathrm{L}_{3-4}$ larvae were exposed to the same amount of fungal spores but provided with two different quantities of food or no food at all. The quantities were based on the study by Koenraadt et al [29] in which it was shown that 0.5 $\mathrm{mg} /$ larva/day adversely affected larval survival. A lower quantity was $0.3 \mathrm{mg} / \mathrm{larva} /$ day which is the standard quantity of food provided to $\mathrm{L}_{3-4}$ larvae in the laboratory. Each replica consisted of six trays. Fifty larvae were added to each tray. Three trays were treated with $10 \mathrm{mg}$ of fungal spores, while the rest served as control. Larvae in one treated and one control tray were provided with food at a rate of $0.5 \mathrm{mg} /$ larva/day $\left(\mathrm{F}_{1}\right)$. Similarly larvae in another control and treated tray were provided with $0.3 \mathrm{mg} / \mathrm{larva} /$ day $\left(\mathrm{F}_{2}\right)$ of food while those in the last two trays had no food $\left(\mathrm{F}_{3}\right)$ at all. Food here refers to Tetramin'. Both mosquito and fungus species were tested. The mortality and/or pupation was recorded for 10 days. The experiment was replicated four times. For each mosquito, all the treatments and replicates were carried out in parallel.

\section{Effect of larval density}

To determine the effect of larval density on fungal induced larval mortality, 50, 150 and $250 \mathrm{~L}_{3-4}$ larvae were added to plastic trays. This resulted in three larval densities i.e. $0.1\left(D_{1}\right), 0.3\left(D_{2}\right)$ and $0.5\left(D_{3}\right)$ larvae $/ \mathrm{cm}^{2}$ [29]. Apart from the three controls $\left(D_{1}, D_{2}\right.$ and $\left.D_{3}\right)$, all the trays were treated with $10 \mathrm{mg}$ of fungus. Larvae were fed with Tetramin $^{\circ}$ at a rate of $0.3 \mathrm{mg} /$ larva/day. Mortality and pupation was taken into account for 10 days post treatment. The six treatments $\left(D_{1}, D_{2}\right.$ and $D_{3}$; both control and fungus treated) were replicated three times for both fungus and mosquito species. The replicates were spread over separate points in time.

\section{Statistical analysis}

The effect of covariates, on the mortality rate of larvae, was analysed using Cox regression [33]. This model describes the increased or decreased likeliness of an event (in this case mortality) to occur, due to a covariate, in terms of hazard ratios (HR). All covariates were treated as time-independent. The p-values were adjusted for multiple comparisons within models and between analysis by comparing the Wald statistics with Chisquare distribution (at degrees of freedom equal to the number of covariates assessed in that model) and Bonferroni correction, respectively.

The model is based on the assumption of proportional hazard, which was tested graphically by plotting the cumulative hazard rates against time, stratified for each covariate. If the resulting curves showed growth in the same shape without crossing, the assumption was satisfied. The assumption was also checked by plotting the log-log survival functions obtained by Cox regression and Kaplan Meier (KM) analysis and confirmed if the resulting line showed a $45^{\circ}$ trend [34]. Larvae that pupated were considered as censored. 
Survival curves of different fungus concentrations, for each mosquito and fungus species, were compared pairwise by KM analysis [35]. One-way ANOVA was employed to determine any significant difference in the wing lengths. All the analyses were performed using SPSS version 15 software (SPSS Inc. Chicago, IL, USA).

\section{Results}

Susceptibility of mosquito species, the effect of fungus species, larval stage and fungus concentration

The HR's in Table 1A represent the hazard of An. stephensi larvae to die at different fungus concentrations as compared to An. gambiae larvae (reference species). As the values were not significant in any case, the results show that An. stephensi and An. gambiae are equally susceptible to both fungi at both early and late larval stage (Figure 1).

In the case of fungus species, HR's in Table 1B show that the larvae that were exposed to B. bassiana had a lower mortality rate as compared to those exposed to M. anisopliae (reference species). However this was apparent only at the $\mathrm{L}_{1-2}$ stage of both An. gambiae and An. stephensi larvae. The HR's of $\mathrm{L}_{3-4}$ stages as compared to $\mathrm{L}_{1-2}$ stages (reference stage), in Table $1 \mathrm{C}$ show

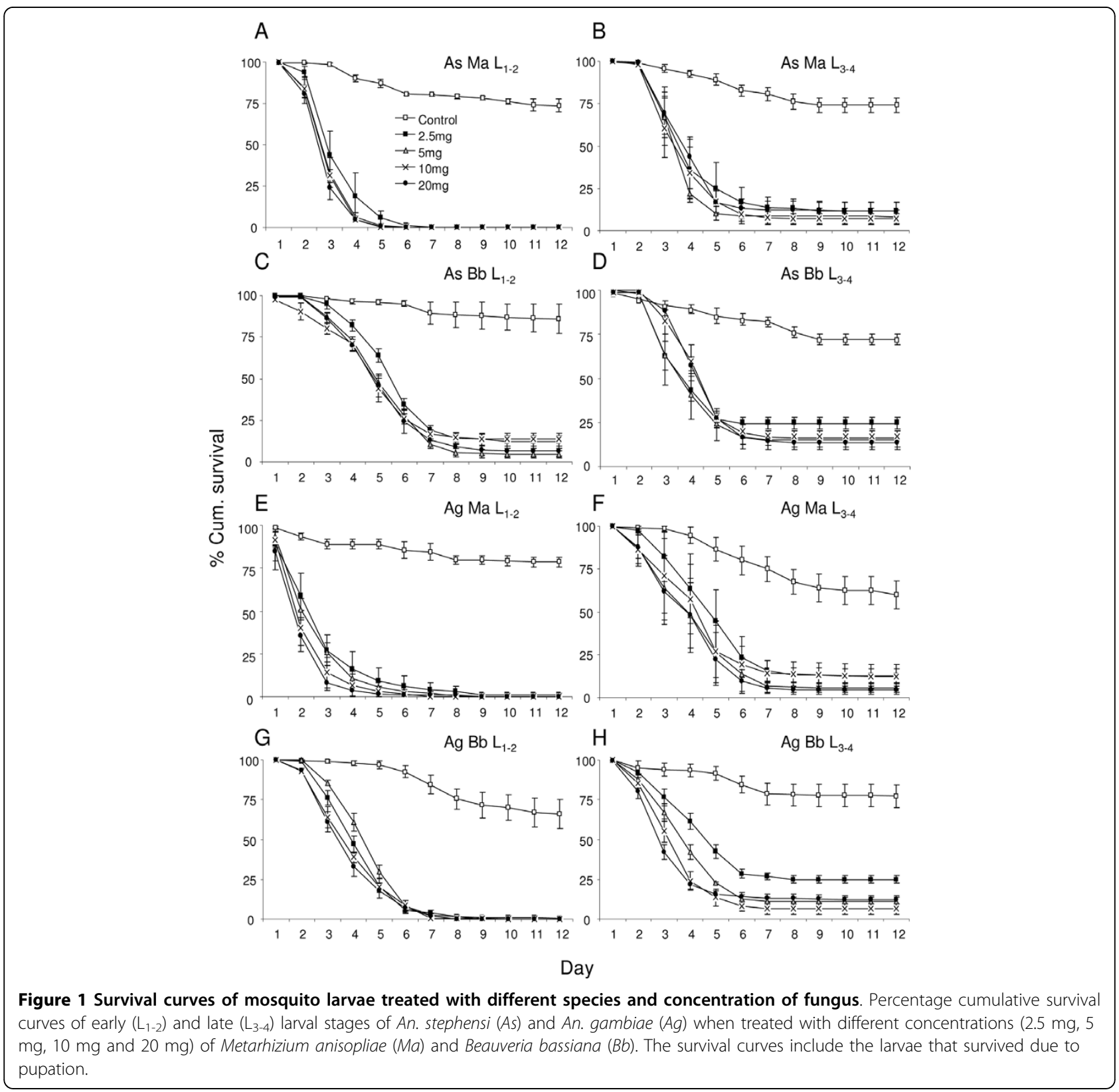


Table 1 Hazard ratios $(95 \% \mathrm{Cl})$ of mosquito larvae treated with different species and concentration of fungus

\begin{tabular}{|c|c|c|c|c|}
\hline \multirow[t]{2}{*}{ A. Mosquito spp. } & \multicolumn{2}{|c|}{ Ma } & \multicolumn{2}{|c|}{$\mathrm{Bb}$} \\
\hline & $L_{1-2}(A-E)$ & $\mathrm{L}_{3-4}(\mathrm{~B}-\mathrm{F})$ & $\mathrm{L}_{1-2}(\mathrm{C}-\mathrm{G})$ & $\mathrm{L}_{3-4}(\mathrm{D}-\mathrm{H})$ \\
\hline 2.5 & $1.01(0.63-1.62)$ & $1.61(1.07-2.43)$ & $1.33(0.82-2.17)$ & $1.36(0.86-2.16)$ \\
\hline 5 & $1.00(0.66-1.69)$ & $1.57(1.04-2.37)$ & $1.87(1.15-3.03)$ & $1.08(0.69-1.69)$ \\
\hline 10 & $0.84(0.52-1.34)$ & $1.57(1.04-2.36)$ & $1.50(0.92-2.44)$ & $0.62(0.40-0.98)$ \\
\hline 20 & $0.76(0.48-1.22)$ & $1.27(0.84-1.90)$ & $1.35(0.83-2.19)$ & $0.51(0.32-0.80)$ \\
\hline \multirow[t]{2}{*}{ B. Fungus spp. } & \multicolumn{2}{|c|}{$\mathrm{Ag}$} & \multicolumn{2}{|c|}{ As } \\
\hline & $\mathrm{L}_{1-2}(\mathrm{E}-\mathrm{G})$ & $\mathrm{L}_{3-4}(\mathrm{~F}-\mathrm{H})$ & $\mathrm{L}_{1-2}(\mathrm{~A}-\mathrm{C})$ & $\mathrm{L}_{3-4}(\mathrm{~B}-\mathrm{D})$ \\
\hline 2.5 & $0.35(0.22-0.54)^{* *}$ & $1.18(0.77-1.81)$ & $0.28(0.16-0.47)^{* *}$ & $1.00(0.64-1.55)$ \\
\hline 5 & $0.26(0.17-0.41)^{* *}$ & $1.15(0.76-1.76)$ & $0.24(0.14-0.41)^{* *}$ & $0.78(0.51-1.20)$ \\
\hline 10 & $0.25(0.16-0.38)^{* *}$ & $1.56(1.02-2.38)$ & $0.24(0.14-0.41)^{* *}$ & $0.61(0.40-0.95)$ \\
\hline 20 & $0.22(0.14-0.35)^{* *}$ & $1.65(1.08-2.52)$ & $0.22(0.13-0.37)^{* *}$ & $0.67(0.43-1.03)$ \\
\hline \multirow[t]{2}{*}{ C. Larval stage } & \multicolumn{2}{|c|}{$\mathrm{Ag}$} & \multicolumn{2}{|c|}{ As } \\
\hline & $\mathrm{Ma}(\mathrm{E}-\mathrm{F})$ & $\mathrm{Bb}(\mathrm{G}-\mathrm{H})$ & $\mathrm{Ma}(\mathrm{A}-\mathrm{B})$ & $\mathrm{Bb}(\mathrm{C}-\mathrm{D})$ \\
\hline 2.5 & $0.18(0.12-0.28)^{* *}$ & $0.57(0.37-0.88)$ & $0.23(0.14-0.37)^{* *}$ & $0.56(0.33-0.93)$ \\
\hline 5 & $0.20(0.13-0.31)^{* *}$ & $0.85(0.55-1.31)$ & $0.22(0.14-0.35)^{* *}$ & $0.46(0.27-0.76)$ \\
\hline 10 & $0.14(0.09-0.22)^{* *}$ & $0.83(0.54-1.27)$ & $0.20(0.12-0.31)^{* *}$ & $0.31(0.18-0.52)^{* *}$ \\
\hline 20 & $0.14(0.09-0.21)^{* *}$ & $0.94(0.61-1.44)$ & $0.16(0.10-0.26)^{* *}$ & $0.31(0.19-0.52)^{* *}$ \\
\hline
\end{tabular}

Mosquito species (An. stephensi (As) versus An. gambiae ( $\mathrm{Ag})$ ), B) fungus species (B. bassiana (Bb) versus M. anisopliae (Ma)) and C) larval stage (Late (L3-4) versus early $\left.\left(\mathrm{L}^{1-2}\right)\right)$, for different concentrations $\left(2.5,5,10,20 \mathrm{mg} / 441 \mathrm{~cm}^{2}\right)$ of the fungi. Asterisks indicate significance $(P<0.01)$ following adjustment for multiple comparison. Letters within parenthesis represent the graphs in Figure 1 that have been compared in the analysis.

that at younger stage are more susceptible to fungal spores. This trend was clear in young larvae treated with $M$. anisopliae.

Kaplan Meier pair wise comparison showed all concentrations to be significantly different from their control (Figure 1, Table 2). Mostly the $2.5 \mathrm{mg}$ treatment was significantly different from 5,10 , and $20 \mathrm{mg}$ for both fungus species. In the case of $B$. bassiana, except for the $\mathrm{L}_{1-2}$ stage of An. stephensi, the $5 \mathrm{mg}$ treatment was significantly different from the 10 and $20 \mathrm{mg}$ treatments. Apart from the B. bassiana treatment of $A n$. gambiae at the $\mathrm{L}_{3-4}$ stage, 10 and $20 \mathrm{mg}$ treatments were not significantly different.

For M. anisopliae the average percentage pupation in the control group of $\mathrm{L}_{1-2} A n$. stephensi was $73.5 \%$ while in the treated groups there was no pupation in all concentrations. In the $\mathrm{L}_{3-4} A n$. stephensi the control group had an average pupation of $74 \%$ and in the treatments it ranged from $7-11.5 \%$. Similarly for $B$. bassiana treatments the average pupation in the control $\mathrm{L}_{1-2} A n$. stephensi was $86 \%$ while at different concentrations it ranged between $0-13 \%$. For the $\mathrm{L}_{3-4}$ An. stephensi the control group had an average pupation of $72 \%$ while in the different B. bassiana treatments it ranged from 9 $-24 \%$. Further on for $M$. anisopliae treatments the average percentage pupation in the control group of $\mathrm{L}_{1-2}$ An. gambiae was $78.5 \%$ while in the treated groups it was $0-1 \%$ for different concentrations. The $\mathrm{L}_{3-4} A n$. gambiae control group had an average pupation of $60 \%$ while in the treatments it ranged from $4-12 \%$. In case of
B. bassiana treatments the average pupation in the control $\mathrm{L}_{1-2}$ An. gambiae was $77 \%$ while at different concentrations it ranged between $0-1 \%$. For the $\mathrm{L}_{3-4} A n$. gambiae the control group had an average pupation of $66 \%$ while in the different $B$. bassiana treatments it ranged from $6.5-25 \%$.

\section{Effect of exposure time}

The larvae exposed to fungus for seven days were considered as the reference group. The HR's (Table 3), therefore, represent the increased or decreased hazard for the larvae when they were exposed to fungus $(M$. anisopliae and B. bassiana) for 0 (control), 1, 3 or 5 days as compared to the larvae exposed for 7 days. Anopheles stephensi and An. gambiae larvae exposed to fungus for 1,3 , and 5 days did not have a significant higher or lower hazard to larvae that were exposed for seven days. In other words 1,3 and 5 days exposure to fungus had the same effect as seven days exposure (Figure 2). The control larvae were at a significantly lower hazard of dying as compared to the larvae exposed for seven days.

There was no significant difference in the wing lengths of adults developing from larvae in the control and treated trays (1, 3, 5 and 7 days exposure) as shown in Figure 3. Some pupae and adults showed fungal infection. The fungus was confirmed as M. anisopliae or B. bassiana by microscopy. Table 4 shows the pupation and adult emergence (\%) in each treatment and the percentage of larvae that showed infection at the pupal or adult stage e.g. 36 An. stephensi (As) pupae developed 
Table 2 Kaplan Meier pair-wise comparison of treatments (control, 2.5, 5, 10 and $20 \mathrm{mg}$ )

\begin{tabular}{|c|c|c|c|c|c|c|c|}
\hline Mosquito spp. & Larval stage & Fungus spp. & Treatment & Control & 2.5 & 5 & 10 \\
\hline \multirow[t]{16}{*}{$\mathrm{Ag}$} & $L_{1-2}$ & $\mathrm{Ma}$ & 2.5 & $* * *$ & & & \\
\hline & & & 5 & $* * *$ & ns & & \\
\hline & & & 10 & $* * *$ & $* * *$ & $* *$ & \\
\hline & & & 20 & $* * *$ & $* * *$ & $* * *$ & ns \\
\hline & & $\mathrm{Bb}$ & 2.5 & $* * *$ & & & \\
\hline & & & 5 & $* * *$ & * & & \\
\hline & & & 10 & $* * *$ & ns & $* * *$ & \\
\hline & & & 20 & $* * *$ & * & $* * *$ & ns \\
\hline & $L_{3-4}$ & $\mathrm{Ma}$ & 2.5 & $* * *$ & & & \\
\hline & & & 5 & $* * *$ & $* * *$ & & \\
\hline & & & 10 & $* * *$ & $* *$ & ns & \\
\hline & & & 20 & $* * *$ & $* * *$ & ns & ns \\
\hline & & $\mathrm{Bb}$ & 2.5 & $* * *$ & & & \\
\hline & & & 5 & $* * *$ & $* *$ & & \\
\hline & & & 10 & $* * *$ & $* * *$ & $* *$ & \\
\hline & & & 20 & $* * *$ & $* * *$ & $* * *$ & $* *$ \\
\hline \multirow[t]{16}{*}{ As } & $L_{1-2}$ & $\mathrm{Ma}$ & 2.5 & $* * *$ & & & \\
\hline & & & 5 & $* * *$ & $* * *$ & & \\
\hline & & & 10 & $* * *$ & $* * *$ & ns & \\
\hline & & & 20 & $* * *$ & $* * *$ & ns & ns \\
\hline & & $\mathrm{Bb}$ & 2.5 & $* * *$ & & & \\
\hline & & & 5 & $* * *$ & $* *$ & & \\
\hline & & & 10 & $* * *$ & $* *$ & ns & \\
\hline & & & 20 & $* * *$ & $* *$ & ns & ns \\
\hline & $L_{3-4}$ & $\mathrm{Ma}$ & 2.5 & $* * *$ & & & \\
\hline & & & 5 & $* * *$ & $* *$ & & \\
\hline & & & 10 & $* * *$ & * & ns & \\
\hline & & & 20 & $* * *$ & ns & * & ns \\
\hline & & $\mathrm{Bb}$ & 2.5 & $* * *$ & & & \\
\hline & & & 5 & $* * *$ & ns & & \\
\hline & & & 10 & $* * *$ & $* *$ & $* * *$ & \\
\hline & & & 20 & $* * *$ & $* * *$ & $* * *$ & ns \\
\hline
\end{tabular}

Early $\left(\mathrm{L}_{1-2}\right)$ and late $\left(\mathrm{L}_{3-4}\right)$ larval stages of An. gambiae $(A g)$ and An. stephensi $(A s)$ treated with $M$. anisopliae $(M a)$ or $B$. bassiana $(B b) .{ }^{*}: P<0.05,{ }^{* *}: P<0.01,{ }^{* * *}: P$ $<0.001, \mathrm{~ns}=$ not significant.

from the larvae exposed to $B$. bassiana spores for 5 days. Among those, four pupae and ten adults showed fungal infection. These ten adults account for nearly $35 \%$ of the total adults that made it to the adult stage.

\section{Effect of food quantity}

Table 5 represents the hazard for larvae treated with fungal spores as compared to untreated larvae (control) provided with the same quantity of food $(0.5,0.3$ or 0 $\mathrm{mg} /$ larva/day). The HR's show that the hazard decreased with decreasing food quantity (Figures 4 and 5). In the fungal treatment where larvae had no food the hazard was 1-2 times higher than that for their control. The larvae that had food available were 4-19 times more likely to acquire a lethal infection than their control counterparts. The overlapping 95\% confidence interval (Table 5) indicates no difference in the hazard of larvae provided with 0.3 or $0.5 \mathrm{mg}$ of food. The HR's were higher in the presence of food rather than in the absence. In the absence of food $100 \%$ of the control larvae died within 3-4 days. The fungal spores kill slowly so by the time the infected larvae died due to both ingested spores and absence of nutrients, the control starving larvae also started to die. This led to a low hazard ratio. In the other two treatments $(0.3$ and 0.5 mg/larva/day) the HR's were high because the survival of the fed-control larvae was also high. The overlapping 95\% confidence interval (Table 5) indicates no difference in the hazard of larvae provided with 0.3 or $0.5 \mathrm{mg}$ of food.

\section{Effect of larval density}

Based on the fact that infection, caused during the first 1-2 days of fungus treatment, accounts for most of the mortality, density was considered a time-independent covariate. For each density, the control was considered 


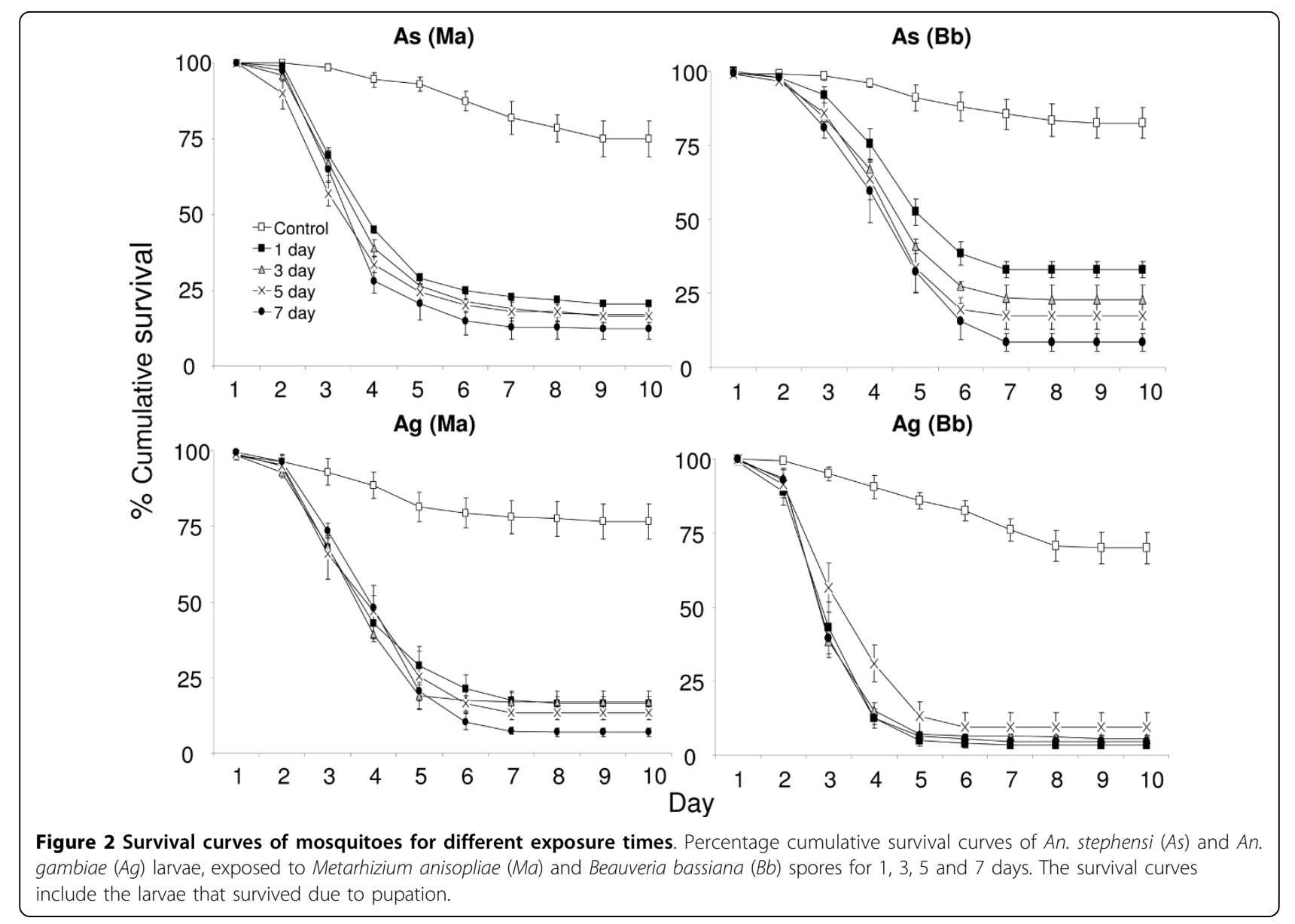

Table 3 Hazard ratios $(95 \% \mathrm{Cl})$ of mosquitoes for different exposure times

\begin{tabular}{cccc}
\hline Mosquito spp. & Fungus spp. & $\begin{array}{c}\text { Treatment Day } \\
\text { (s) }\end{array}$ & HR (95\% Cl) \\
\hline $\mathrm{Ag}$ & $\mathrm{Ma}$ & 0 & $0.30(0.22-0.42)^{*}$ \\
& 1 & $0.94(0.74-1.19)$ \\
& 3 & $1.14(0.92-1.42)$ \\
& 5 & $0.99(0.79-1.24)$ \\
& $\mathrm{Bb}$ & 0 & $0.12(0.08-0.17)^{*}$ \\
& 1 & $0.97(0.80-1.19)$ \\
& 3 & $0.96(0.79-1.17)$ \\
& & 5 & $0.79(0.65-0.97)$ \\
& & 0 & $0.19(0.14-0.27)^{*}$ \\
& $\mathrm{Ma}$ & 1 & $1.01(0.79-1.28)$ \\
& & 3 & $0.96(0.75-1.23)$ \\
& & 5 & $1.11(0.87-1.43)$ \\
& $\mathrm{Bb}$ & 0 & $0.17(0.12-0.25)^{*}$ \\
& 1 & $0.73(0.58-0.92)$ \\
& 3 & $0.81(0.66-1.01)$ \\
& 5 & $1.07(0.86-1.32)$ \\
\hline
\end{tabular}

Hazard ratio (HR) of An. gambiae ( $\mathrm{Ag}$ ) and An. stephensi (As) larvae of the control ( 0 day) and treatments (exposed to M. anisopliae (Ma) or B. bassiana $(B b)$ spores for 1,3 and 5 days) as compared to exposure for 7 days. ${ }^{*} P<0.05$, adjusted for multiple comparison. as the reference i.e. the HRs in Table 6 represent the hazard of the larvae treated with fungus compared to untreated larvae at the same density. Except for the $M$. anisopliae treatment of An. gambiae the HRs increased with an increase in density (Figures 6 and 7). Increase in HRs indicates that with increasing larval density the mortality rate increases. However, the overlapping $95 \%$ CI's (Table 6) indicate that, although such trends exist, this was not significant in all cases.

\section{Discussion}

This study shows the susceptibility An. stephensi and An. gambiae larvae to $M$. anisopliae and B. bassiana and how larval stage, fungus species and fungus concentration can influence the mortality rate. In addition, it also provides an insight into the impact of exposure duration, quantity of food available, and larval density on the mortality rate.

Both mosquito species were equally susceptible to $M$. anisopliae and B. bassiana spores. M. anisopliae and $B$. bassiana spores act as midgut toxins and enter the body mainly through the mouth. When applied over the water surface they are readily available to the larvae of 


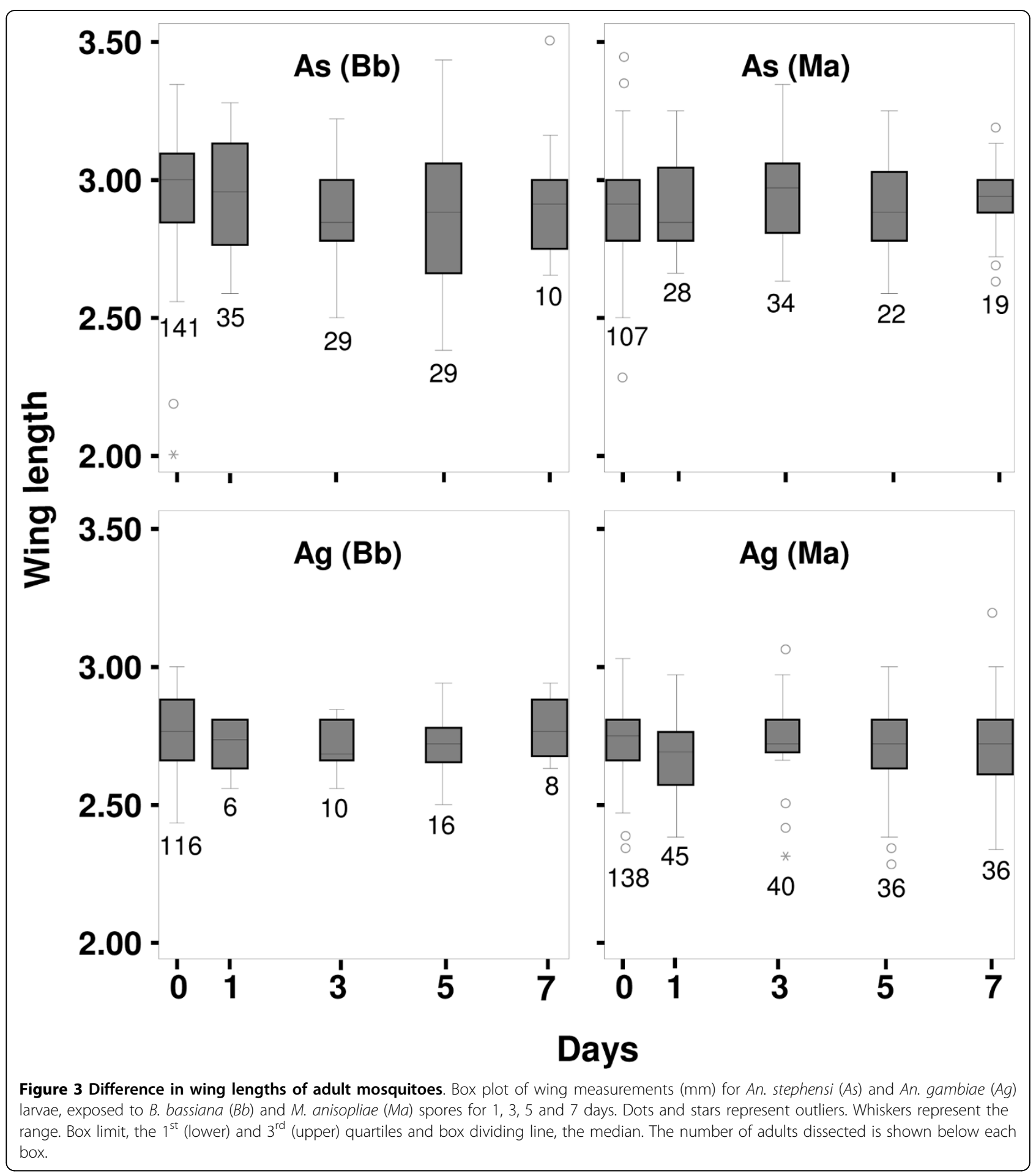

An. stephensi and An. gambiae as well as other anopheline species, which are surface-feeders. Because anophelines have similar filtering and ingestion rates both $A n$. stephensi and An. gambiae were equally affected [18,36-40].
The lower hazard of B. bassiana spores as compared to $M$. anisopliae spores at the $\mathrm{L}_{1-2}$ stage cannot be due to the spore size as in this regard M. anisopliae (2.5-3.5 $\mu \mathrm{m})$ and $B$. bassiana $(2-3 \mu \mathrm{m})$ are comparable and within the range of particle size appropriate for 
Table 4 The number and percentage of pupae and adults that showed fungus infection

\begin{tabular}{|c|c|c|c|c|c|c|c|c|c|c|}
\hline \multirow[t]{2}{*}{$\begin{array}{l}\text { Mosquito } \\
\text { spp. }\end{array}$} & \multirow[t]{2}{*}{$\begin{array}{l}\text { Fungus } \\
\text { spp. }\end{array}$} & \multirow[t]{2}{*}{$\begin{array}{l}\text { Treatment } \\
\text { (days) }\end{array}$} & \multicolumn{2}{|c|}{ Pupation } & \multicolumn{2}{|c|}{$\begin{array}{l}\text { Pupae showing } \\
\text { infection }\end{array}$} & \multicolumn{2}{|c|}{ Adult emergence } & \multicolumn{2}{|c|}{$\begin{array}{l}\text { Adults showing } \\
\text { infection }\end{array}$} \\
\hline & & & $\mathrm{n}$ & $\% *$ & $\mathbf{N}$ & $\%^{*}$ & $\mathrm{n}$ & $\% *$ & $\mathbf{n}$ & \%* \\
\hline \multirow[t]{10}{*}{$\overline{\mathrm{Ag}}$} & $\mathrm{Ma}$ & 0 & 150 & 74.3 & 0 & 0 & 138 & 68.3 & 0 & 0 \\
\hline & & 1 & 52 & 26.5 & 0 & 0 & 45 & 23.0 & 3 & 1.5 \\
\hline & & 3 & 49 & 23.6 & 0 & 0 & 40 & 19.2 & 0 & 0 \\
\hline & & 5 & 42 & 21.2 & 0 & 0 & 36 & 18.1 & 5 & 2.5 \\
\hline & & 7 & 37 & 18.3 & 0 & 0 & 36 & 17.8 & 1 & 0.5 \\
\hline & $\mathrm{Bb}$ & 0 & 127 & 70.6 & 0 & 0 & 116 & 64.6 & 0 & 0 \\
\hline & & 1 & 7 & 3.4 & 0 & 0 & 6 & 2.9 & 0 & 0 \\
\hline & & 3 & 11 & 5.5 & 0 & 0 & 10 & 5 & 1 & 0.5 \\
\hline & & 5 & 19 & 8.9 & 0 & 0 & 16 & 7.5 & 5 & 2.3 \\
\hline & & 7 & 9 & 4.3 & 1 & 0.5 & 8 & 3.9 & 0 & 0 \\
\hline \multirow[t]{10}{*}{ As } & Ma & 0 & 153 & 72.5 & 0 & 0 & 107 & 50.7 & 0 & 0 \\
\hline & & 1 & 52 & 25.3 & 2 & 1 & 28 & 14.1 & 4 & 2 \\
\hline & & 3 & 48 & 24.9 & 2 & 1 & 34 & 17.7 & 9 & 4.6 \\
\hline & & 5 & 40 & 22.2 & 3 & 1.7 & 22 & 13.3 & 7 & 3.9 \\
\hline & & 7 & 38 & 19.7 & 1 & 0.5 & 19 & 11.1 & 1 & 0.5 \\
\hline & $\mathrm{Bb}$ & 0 & 159 & 82 & 0 & 0 & 141 & 72.7 & 0 & 0 \\
\hline & & 1 & 66 & 34.9 & 6 & 3.2 & 35 & 18.5 & 5 & 2.6 \\
\hline & & 3 & 51 & 24.9 & 10 & 4.9 & 29 & 14.1 & 8 & 3.9 \\
\hline & & 5 & 36 & 17.6 & 4 & 2 & 29 & 14.1 & 10 & 4.9 \\
\hline & & 7 & 17 & 8.5 & 2 & 1 & 10 & 5 & 1 & 0.5 \\
\hline
\end{tabular}

An. gambiae $(\mathrm{Ag})$ and An. stephensi $(A s)$ that developed from the larvae $(\mathrm{n}=200)$ treated with fungus $(M$. anisopliae $(M a)$ or B. bassiana $(B b))$ spores. * Percentages are based on total number of larvae treated.

anopheline collecting-filtering feeding mode $(0.45 \mu \mathrm{m}-1$ $\mathrm{mm})[15,38]$. However, the difference in the rapidity of vegetative growth found in $M$. anisopliae and B. bassiana may cause the difference in the observed effect of the two fungi. Metarhizium anisopliae is characterized

Table 5 Hazard ratios $(95 \% \mathrm{Cl})$ of mosquitoes provided with different quantities of food

\begin{tabular}{llll}
\hline Mosquito spp. & Fungus spp. & $\begin{array}{l}\text { Food provision } \\
\text { treatment }\end{array}$ & HR (95\% Cl) \\
\hline $\mathrm{Ag}$ & $\mathrm{Ma}$ & 0.5 & $5.25(2.97-9.25)^{\mathrm{a}}$ \\
& & 0.3 & $4.30(3.24-5.69)^{\mathrm{a}}$ \\
& $\mathrm{Bb}$ & 0.5 & $1.98(1.59-2.46)^{\mathrm{b}}$ \\
& & 0.3 & $4.40(2.88-6.73)^{\mathrm{a}}$ \\
& & 0 & $6.73(4.79-9.45)^{\mathrm{a}}$ \\
$\mathrm{As}$ & $\mathrm{Ma}$ & 0.5 & $2.57(2.07-3.20)^{\mathrm{b}}$ \\
& & 0.3 & $5.25(2.97-9.25)^{\mathrm{a}}$ \\
& $\mathrm{Bb}$ & 0 & $7.04(5.02-9.87)^{\mathrm{a}}$ \\
& 0.5 & $1.90(1.54-2.34)^{\mathrm{b}}$ \\
& & $19.21(9.45-39.03)$ \\
& 0.3 & $5.05(3.56-7.16)^{\mathrm{b}}$ \\
& 0 & $1.22(1.00-1.49)^{\mathrm{c}}$ \\
\hline
\end{tabular}

Hazard ratio (HR) of treated (10 mg, M. anisopliae (Ma) or B. bassiana (Bb)) An. gambiae $(\mathrm{Ag})$ and $A n$. stephensi $(A s)$ larvae compared to untreated larvae provided with the same quantity of food $(0.5,0.3$ or $0 \mathrm{mg} / \mathrm{larva} /$ day). HR's with letters in common indicate overlapping of $95 \%$ confidence limits. by a rapid vegetative growth although at the expense of sporulation, while $B$. bassiana has a slow vegetative growth with high total sporulation [41]. Slow vegetative growth may be associated with the slow release of endotoxins inside the larval body and, thus, a delayed mortality.

The reason for the difference in lethal effects of $M$. anisopliae and B. bassiana at the younger $\left(\mathrm{L}_{1-2}\right)$ stage and the reduced susceptibility of the older $\left(\mathrm{L}_{3-4}\right)$ stage can be considered together. The younger stage has a longer developmental time ahead until pupation, during which they feed and moult two to three times. Larvae are more vulnerable to infection immediately after ecdysis because of the soft cuticle. Younger larval stages thus have an increased probability of acquiring an infection. Late larval stages, on the other hand, have reduced food intake and a thicker cuticle and thus it is less likely that spores would enter or penetrate their body $[16,42,43]$.

Dry spores were used and dusted on the water surface because they are more effective than the normal laboratory formulations $(0.1 \%$ Tween 80 solution) that reduce the clumping but cause the spores to sink as the water surface is the main foraging site of Anopheles larvae [18,38,44]. Although there was a difference in the effect of fungal concentrations, this was not proportional. The fungal spores are hydrophobic and when applied over the water 


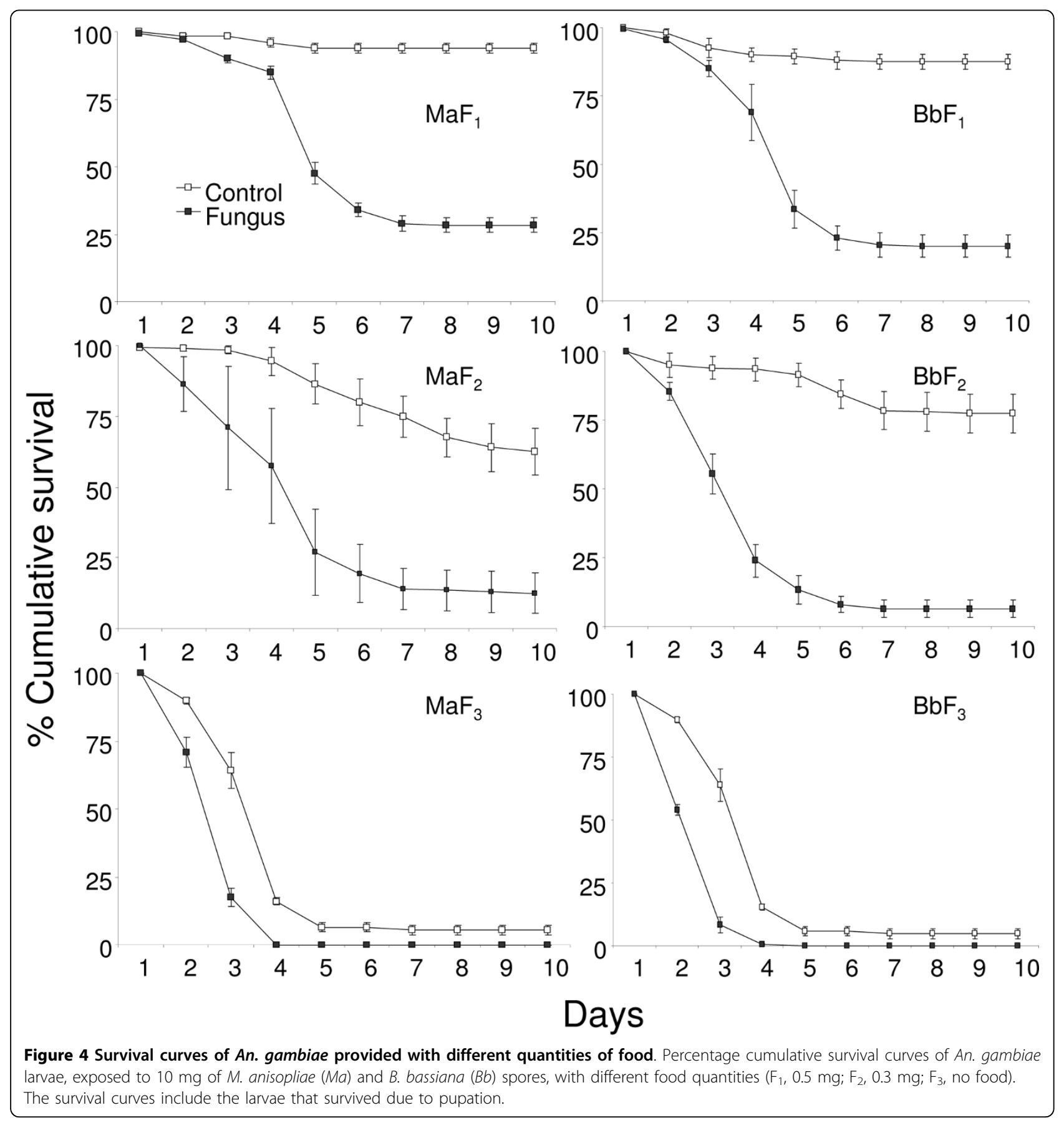

surface without a surfactant they clump together into masses that become dense over time. Larvae may have rejected the spore mass as food most likely because of large clump size and the density of the mass made spore attachment avoidable. As a result, high concentrations did not provide a better spatial and temporal coverage that could have resulted in increased mortality rate. To achieve the full benefits of biological control it is better to use fungal spores rather than extracted endotoxins [45]. When spores enter the larval body through the mouth or siphon they mechanically block these passages while a few attach to the interior. The attached spores germinate releasing endotoxins as well as damaging the larval tissues with their vegetative growth [46]. In this case there is a whole spectrum of offence that has to be tackled by the larval immune system. The more variable the modes of action, the lower is the probability that resistance will develop against the control agent [47].

The exposure time experiment showed that one day exposure to fungus spores has more or less the same 


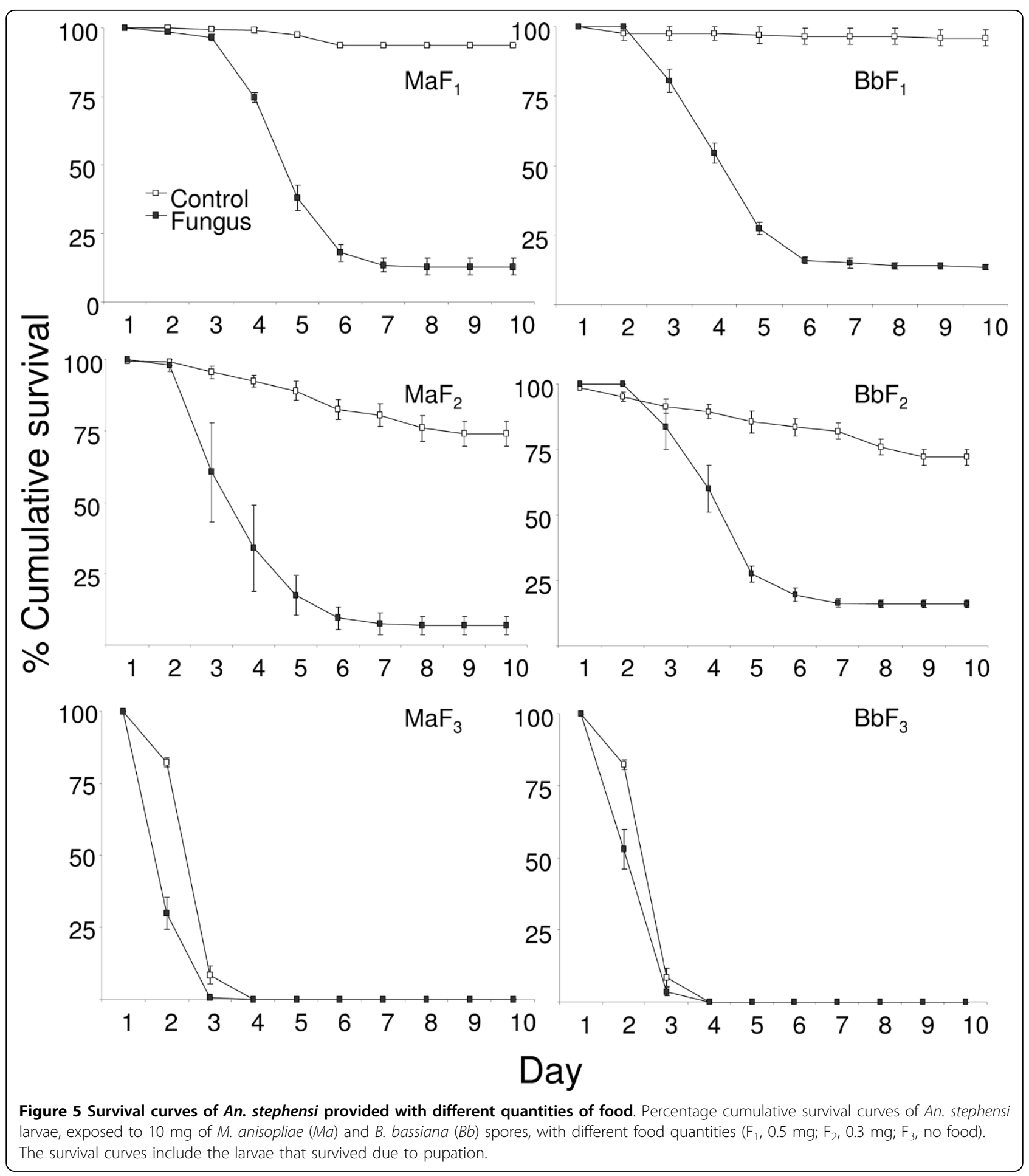

effect as an exposure of seven days. One explanation would be the clumping of spores over time meaning that the spore coverage and thus its effect is not the same over time. Another explanation may be the ingestion rate of larvae. Normally food passes through the larval guts in 1-1.5 hours [37,38]. Within 24 hours of exposure, swollen (ready to germinate) spores can be detected in the gut and even in exuviae. Although mortality occurs after 4 days, it takes only one day for the spores to penetrate the tissues [30]. As a result, even if the larvae are shifted to un-treated water after a day they carry a sufficient amount of spores required for a 
Table 6 Hazard ratios $(95 \% \mathrm{Cl})$ of mosquitoes at different larval densities

\begin{tabular}{|c|c|c|c|}
\hline Mosquito spp. & Fungus spp. & Larval density & HR $(95 \% \mathrm{Cl})$ \\
\hline \multirow[t]{6}{*}{$\mathrm{Ag}$} & $\mathrm{Ma}$ & 0.1 & $11.87 \underset{\mathrm{a}}{(6.62-21.31)}$ \\
\hline & & 0.3 & $4.37(3.06-6.23)^{b}$ \\
\hline & & 0.5 & $3.73(3.07-4.59)^{b}$ \\
\hline & $\mathrm{Bb}$ & 0.1 & $3.13(2.15-4.54)^{a}$ \\
\hline & & 0.3 & $8.39(6.40-10.10)^{b}$ \\
\hline & & 0.5 & $\begin{array}{c}29.32(20.72- \\
41.48)^{c}\end{array}$ \\
\hline \multirow[t]{6}{*}{ As } & $\mathrm{Ma}$ & 0.1 & $15.12 \underset{a}{(8.42-27.16)}$ \\
\hline & & 0.3 & $\begin{array}{c}61.13(27.30- \\
136.89)^{b}\end{array}$ \\
\hline & & 0.5 & $\begin{array}{c}73.66(34.98- \\
155.11)^{b}\end{array}$ \\
\hline & $\mathrm{Bb}$ & 0.1 & $13.88 \underset{a}{(7.44-25.89)}$ \\
\hline & & 0.3 & $\begin{array}{c}47.7(21.27- \\
106.99)^{a, b}\end{array}$ \\
\hline & & 0.5 & $\begin{array}{c}63.23(29.97- \\
133.41)^{b}\end{array}$ \\
\hline
\end{tabular}

Hazard ratios (HR) of An. gambiae ( $A g)$ and An. stephensi (As) larvae treated with $M$. anisopliae $(M a)$ or $B$. bassiana $(B b)$ spores compared to un-treated larvae at the same density $\left(0.1,0.3\right.$ or 0.5 larvae $\left./ \mathrm{cm}^{2}\right)$. HR's with letters in common indicate overlapping of $95 \%$ confidence limits. fatal infection. This is useful as in field application dry spores may loose their virulence within days due to environmental conditions (notably UV radiation).

Although the larvae exposed to B. bassiana had a lower mortality rate as compared to the ones exposed to $M$. anisopliae, the proportion of larvae that made it to the adult stage was equal. As a result, if used, both fungi will equally contribute to reducing malaria transmission. For a better concentration effect it is important to have a formulation that spreads the spores while leaving them at the surface. It will not only facilitate the application but also decrease the required amount of spores. Considering the entry routes of spores into the larval body, it is important to have an organic and dry formulation for the control of anopheline species $[18,41]$. The formulation is also necessary to increase the persistence of the fungal spores. Fungal spores are sensitive to temperature, humidity and ultraviolet radiation. High relative humidity triggers germination in the spores and is therefore likely to play a negative role when spores are applied over the water surface $[48,49]$. Although oneday exposure is enough to cause significant mortality, the lack of a residual effect is a big disadvantage. This can possibly be solved by selection for tolerant isolates and formulations [22,48-51].

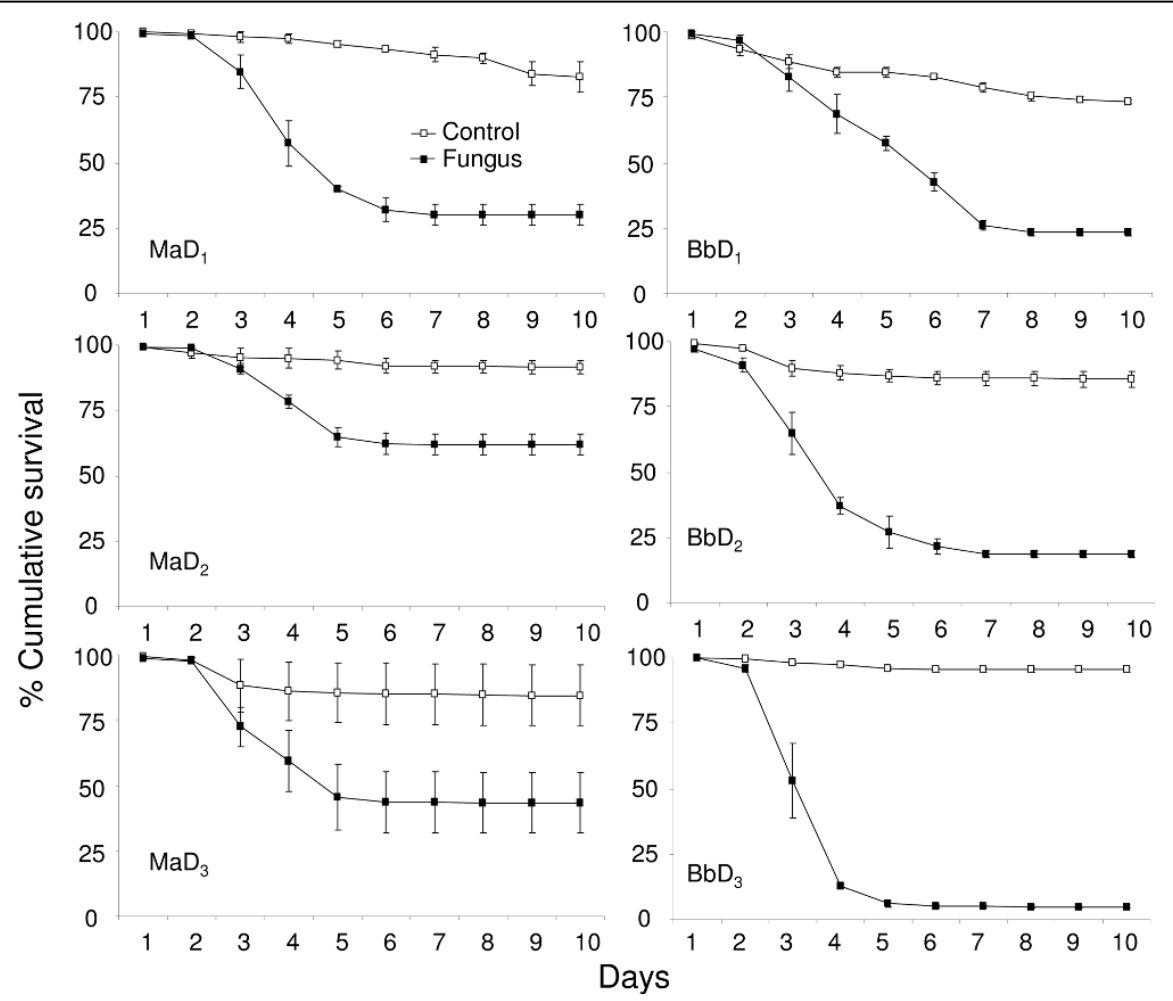

Figure 6 Survival curves of $\boldsymbol{A n}$. gambiae at different densities. Percentage cumulative survival curves of An. gambiae larvae, exposed to 10 $\mathrm{mg}$ of M. anisopliae (Ma) and B. bassiana (Bb) spores, at different densities $\left(D_{1}, 0.5\right.$ larvae/ $\mathrm{cm}^{2} ; D_{2}, 0.3$ larvae/ $\mathrm{cm}^{2} ; D_{3}, 0.1$ larvae/ $\left.\mathrm{cm}^{2}\right)$. The survival curves include the larvae that survived due to pupation. 


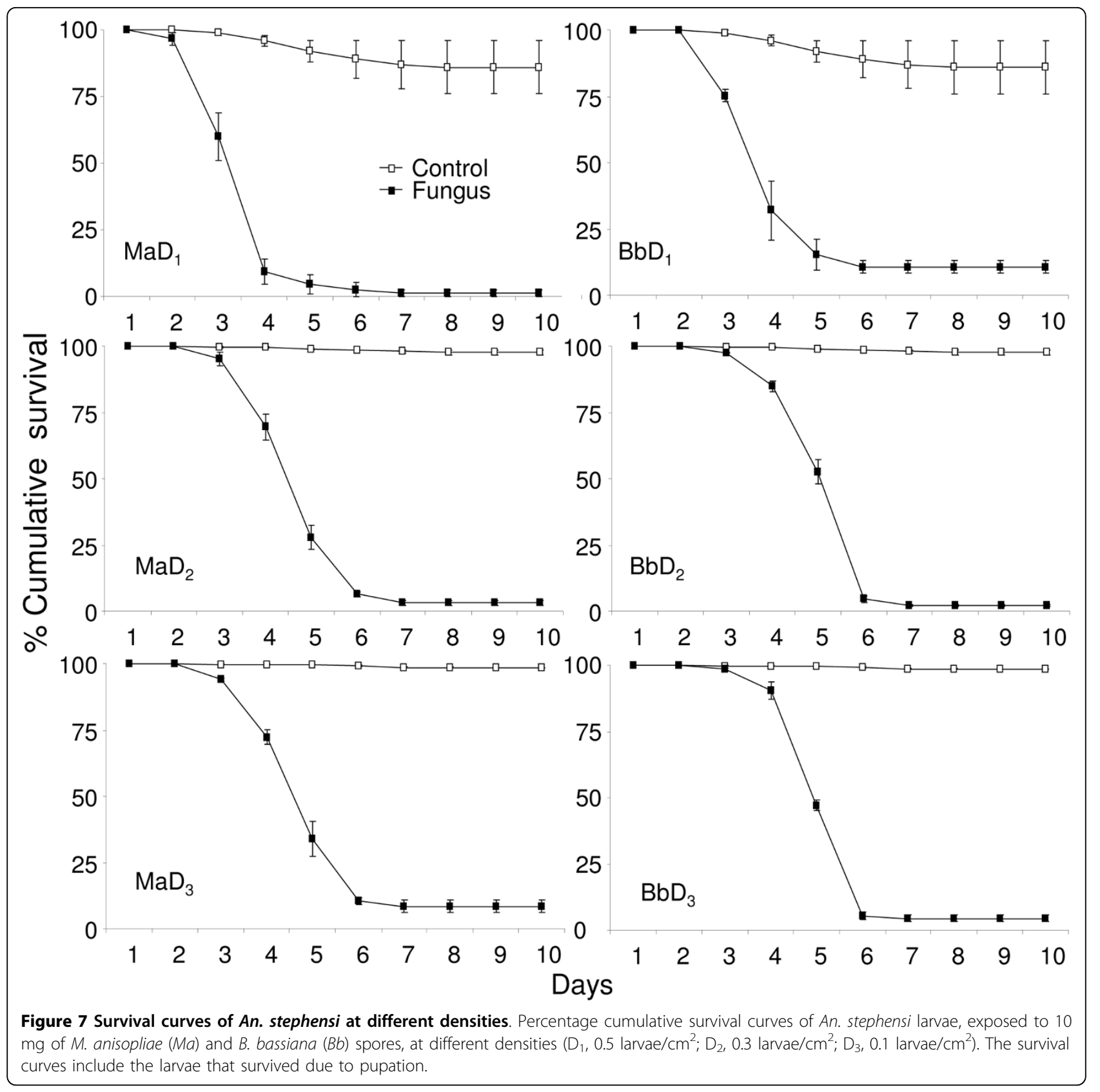

In some treatments up to $9 \%$ of the total fungusinfected larvae developed into pupae or adults that showed fungus infection. The passage of infection from the larvae to pupae and/or adult was also observed by Lord et al, Wilson et al and Sandhu et al [16,19,52]. This study reports the transfer of $M$. anisopliae and $B$. bassiana infection from the larvae to the pupae and adults of both An. stephensi and An. gambiae. Studies that deal with the immune system of insects during metamorphosis show increased anti-bacterial activities
$[53,54]$. However, there is not much information about anti-fungal activity. Extracts from the medicinal plant, Leuzea carthamoides, known to contain 20-hydroxyecdysone showed anti-bacterial effect but in the study anti-fungal effects were not tested [55]. In another study juvenile hormone $(\mathrm{JH})$ showed no effect on fungal growth [56]. The transfer of fungal infection may be due to the absent or moderate anti-fungal activity during metamorphosis. This ability of the fungus, to transfer from one life-cycle stage to the other, through the 
extreme histological changes during metamorphosis is very interesting as fungal exposure at a late larval stage can result in adults with reduced longevity.

At the tested concentration (10 mg) of fungal spores, the hazard increased with increase in larval density. The increasing hazard might be the result of increased larval mobility, which in turn increases the chance of contacting fungus spores and causing stress due to competition for space. At a low density, on the other hand, larvae have a reduced chance of contacting fungus spores because of less motility. However, it might be so that with a lower fungus concentration the larvae at higher density show low mortality due to reduced spore-share per larva [57]. The concentration of fungus is therefore critical. The difference in the $M$. anisopliae treatment of An. gambiae is probably because of more $\mathrm{L}_{4}$ larvae in the cohort as by the $3^{\text {rd }}$ day pupation was already $40 \%$ in $\mathrm{D}_{2}$ and $30 \%$ in $\mathrm{D}_{3}$ fungus-treated trays.

In the laboratory both fungal species show potential as larval control agents. To check their aptitude in the field, trials need to be conducted under natural conditions where, apart from the persistence and efficacy of the spores, the fungal species need to be observed for their non-target effect. Non-target effects of $M$. anisopliae and B. bassiana have been reported in aquatic environments [58-60]. However, these tests were done at extreme circumstances, which are highly unlikely under field conditions as fungal spores themselves are sensitive to environmental factors $[46,48,49]$. It is therefore important to test the non-target effects of these fungi in more realistic settings. As far as humans are concerned clinical cases have been rare and associated with mass exposure and immunodeficiency $[15,61]$. Thus, although any adverse effects on human are highly unlikely studies need to be done on formulations and delivery methods that reduce the chances of human and fungal contact.

\section{Conclusions}

It is clear that both M. anisopliae and B. bassiana are highly effective in reducing larval survival and adult emergence. At times when insecticide resistance is increasing it is important to have a wider option of new biological and environmentally friendly control agents. However studies need to be carried out to develop efficient formulations and delivery methods for these fungi. Fungi might than present a new generation of larval control agents.

\section{Acknowledgements}

We thank MR4 for providing An. stephensi eggs and Leo Koopman, André Gidding and Frans van Aggelen for rearing the An. gambiae mosquitoes. Frank van Breukelen and Mgeni Jumbe are acknowledged for providing Metarhizium and Beauveria spores. We thank Dr Lia Hemerik for her guidance with statistical analysis. Tullu Bukhari is funded by HEC, Pakistan, through NUFFIC (the Netherlands).

\section{Author details}

${ }^{1}$ Laboratory of Entomology, Wageningen University, Wageningen, the Netherlands. ${ }^{2}$ Division of Infectious Diseases, Tropical Medicine AIDS, Academic Medical Center, University of Amsterdam, the Netherlands.

\section{Authors' contributions}

TB and AM carried out the experimental work; TB performed the statistical analysis and drafted the manuscript. CJMK helped with the statistical analyses and drafting the manuscript. WT provided scientific guidance in interpretation of the findings. BGJK provided overall supervision in the study design, coordination and drafting of the manuscript. All authors read and approved the final manuscript.

\section{Competing interests}

The authors declare that they have no competing interests.

Received: 8 September 2009

Accepted: 19 January 2010 Published: 19 January 2010

\section{References}

1. Gu W, Utzinger J, Novak RJ: Habitat-based larval interventions: A new perspective for malaria control. Am J Trop Med Hyg 2008, 78:2-6.

2. Killeen GF, Fillinger U, Kiche I, Gouagna LC, Knols BGJ: Eradication of Anopheles gambiae from Brazil: lessons for malaria control in Africa. Lancet Infect Dis 2002, 2:618-627.

3. Killeen GF, Fillinger U, Knols BGJ: Advantages of larval control for African malaria vectors: Low mobility and behavioural responsiveness of immature mosquito stages allow high effective coverage. Malar J 2002, $1: 8$

4. Utzinger J, Tanner M, Kammen DM, Killeen GF, Singer BH: Integrated programme is key to malaria control. Nature 2002, 419:431-431.

5. Fillinger $U$, Lindsay SW: Suppression of exposure to malaria vectors by an order of magnitude using microbial larvicides in rural Kenya. Trop Med Int Health 2006, 11:1629-1642

6. Utzinger J, Tozan $Y$, Singer BH: Efficacy and cost-effectiveness of environmental management for malaria control. Trop Med Int Health 2001, 6:677-687.

7. Baragatti M, Fournet F, Henry M-C, Assi S, Ouedraogo H, Rogier C, Salem G: Social and environmental malaria risk factors in urban areas of Ouagadougou, Burkina Faso. Malar J 2009, 8:13.

8. Fillinger $U$, Kannady K, William G, Vanek M, Dongus S, Nyika D, Geissbuhler Y, Chaki P, Govella N, Mathenge E, Singer B, Mshinda H, Lindsay S, Tanner M, Mtasiwa D, de Castro M, Killeen G: A tool box for operational mosquito larval control: preliminary results and early lessons from the Urban Malaria Control Programme in Dar es Salaam, Tanzania. Malar J 2008, 7:20

9. Hay SI, Guerra CA, Tatem AJ, Atkinson PM, Snow RW: Urbanization, malaria transmission and disease burden in Africa. Nat Rev Microbiol 2005, 3:8190

10. Keiser J, Utzinger J, Caldas de Castro M, Smith TA, Tanner M, Singer BH: Urbanization in sub-saharan Africa and implication for malaria control. Am J Trop Med Hyg 2004, 71:118-127.

11. Geissbuhler Y, Kannady K, Chaki PP, Emidi B, Govella NJ, Mayagaya V Kiama M, Mtasiwa D, Mshinda H, Lindsay SW, Tanner M, Fillinger U, de Castro MC, Killeen GF: Microbial larvicide application by a large-scale, community-based program reduces malaria infection prevalence in urban Dar Es Salaam, Tanzania. PLoS ONE 2009, 4:e5107.

12. Wirth MC, Jiannino JA, Federici BA, Walton WE: Synergy between toxins of Bacillus thuringiensis subsp. israelensis and Bacillus sphaericus. J Med Entomol 2004, 41:935-941.

13. Yuan Z, Zhang Y, Cai Q, Liu EY: High-level field resistance to Bacillus sphaericus C3-41 in Culex quinquefasciatus from southern China. Biocontrol Sci Techn 2000, 10:41-49.

14. Lord JC: From Metchnikoff to Monsanto and beyond: The path of microbial control. J Invertebr Pathol 2005, 89:19-29.

15. de Hoog GS, Guarro J, Gené J, Figueras MJ: Atlas of clinical fungi Utrecht: Centraalbureau voor Schimmelcultures, 22000

16. Sandhu SS, Rajak RC, Sharma M: Bioactivity of Beauveria bassiana and Metarhizium anisopliae as pathogens of Culex tritaeniorhynchus and Aedes aegypti: effect of instar, dosages and time. Indian J Microbiol 1993 33:191-194. 
17. Clark TB, Kellen WR, Fukuda T, Lindegren JE: Field and laboratory studies on the pathogenicity of the fungus Beauveria bassiana to three genera of mosquitoes. J Invertebr Pathol 1968, 11:1-7.

18. Ramoska WA, Watts S, Watts HA: Effects of sand formulated Metarhizium anisopliae spores on larvae of three mosquito species. Mosa News 1981, 41:725-728.

19. Wilson ML, Agudelo-Silva F, Spielman A: increased abundance, size, and longevity of food-deprived mosquito populations exposed to a fungal larvicide. Am J Trop Med Hyg 1990, 43:551-556.

20. Alves SB, Alves LFA, Lopes RB, Pereira RM, Vieira SA: Potential of some Metarhizium anisopliae isolates for control of Culex quinquefasciatus (Dipt., Culicidae). J Appl Entomol 2002, 126:504-509.

21. Daoust RA, Roberts DW: Virulence of natural and insect-passaged strains of Metarhizium anisopliae to mosquito larvae. J Invertebr Pathol 1982, 40:107-117.

22. Daoust RA, Ward MG, Roberts DW: Effect of formulation on the virulence of Metarhizium anisopliae conidia against mosquito larvae. J Invertebr Pathol 1982, 40:228-236.

23. Miranpuri GS, Khachatourians GG: Infection sites of the entomopathogenic fungus Beauveria bassiana in the larvae of the mosquito Aedes aegypti. Entomologia Experimentalis et Applicata 1991, 59:19-27.

24. Luz C, Tai MHH, Santos AH, Rocha LFN, Albernaz DAS, Silva HHG: Ovicidal activity of entomopathogenic Hyphomycetes on Aedes aegypti (Diptera: Culicidae) under laboratory conditions. J Med Entomol 2007, 44:799-804.

25. Luz C, Tai MHH, Santos AH, Silva HHG: Impact of moisture on survival of Aedes aegypti eggs and ovicidal activity of Metarhizium anisopliae under laboratory conditions. Mem Inst Oswaldo Cruz, Rio de Janeiro 2008, 103:214-215.

26. Scholte EJ, Ng'habi K, Kihonda J, Takken W, Paaijmans K, Abdulla S, Killeen GF, Knols BG: An entomopathogenic fungus for control of adult African malaria mosquitoes. Science 2005, 308:1641-1642.

27. Farenhorst M, Farina D, Scholte E-J, Takken W, Hunt RH, Coetzee M, Knols BGJ: African water storage pots for the delivery of the entomopathogenic fungus Metarhizium anisopliae to the malaria vectors Anopheles gambiae s.s. and Anopheles funestus. Am J Trop Med Hyg 2008, 78:910-916.

28. Odiere M, Bayoh MN, Gimnig J, Vulule J, Irungu L, Walker E: Sampling outdoor, resting Anopheles gambiae and other mosquitoes (Diptera: Culicidae) in Western Kenya with clay pots. J Med Entomol 2007, 44:14-22.

29. Koenraadt CJ, Majambere S, Hemerik L, Takken W: The effects of food and space on the occurrence of cannibalism and predation among larvae of Anopheles gambiae s.l. Entomol Exp Appl 2004, 112:125-134.

30. Miranpuri GS, Khachatourians GG: Infection sites of the entomopathogenic fungus Beauveria bassiana in the larvae of the mosquito Aedes aegypti. Entomol Exp Appl 1991, 59:19-27.

31. Benedict MQ: Methods in Anopheles research Atlanta, USA: Malaria Research and Reference Reagent Resource Center 2007.

32. Takken W, Klowden MJ, Chambers GM: Effect of body size on host seeking and blood meal utilization in Anopheles gambiae sensu stricto (Diptera: Culicidae): the disadvantage of being small. J Med Entomol 1998, 35:639-645.

33. Cox DR: Regression models and life tables (with discussion). J Royal Statist Soc 1972, B:187-220.

34. Haccou $P$, Hemerik $L$ : The influence of larval dispersal in the cinnabar moth ( Tyria jacobaeae) on predation by the red wood ant (Formica polyctena): an analysis based on the proportional hazards model. J Anim Ecol 1985, 54:755-769.

35. Kleinbaum DG, Klein M: Survival analysis: a self-learning text New York, NY: Springer 2005

36. Aly C: Filtration rates of mosquito larvae in suspensions of latex microspheres and yeast cells. Entomologia Experimentalis et Applicata 1988, 46:55-61.

37. Aly C, Mulla MS: Orientation and ingestion rates of larval Anopheles albimanus in response to floating particles. Entomol Exp Appl 1986, 42:8390.

38. Merritt RW, Dadd RH, Walker ED: Feeding behavior, natural food, and nutritional relationships of larval mosquitoes. Ann Rev Entomol 1992, 37:349-374.

39. O'Malley CM: The biology of Anopheles quadrimaculatus Say. Proc 79th Ann Meeting NJMCA, Inc: 1992 1992, 136-144.
40. Ramoska WA, Hopkins TL: Effects of mosquito larval feeding behavior on Bacillus sphaericus efficacy. J Invertebr Pathol 1981, 37:269-272.

41. Sun J, Fuxa JR, Henderson G: Sporulation of Metarhizium anisopliae and Beauveria bassiana on Coptotermes formosanus and in vitro. $J$ Invertebr Pathol 2002, 81:78-85.

42. Apperson CS, Federich BA, Tarver FR, Stewart W: Biotic and abiotic parameters associated with an epizootic of Coelomomyces punctatus in a larval population of the mosquito Anopheles quadrimaculatus. I Invertebr Pathol 1992, 60:219-228.

43. Lord JC, Fukuda T: A Leptolegnia (Saprolegniales) pathogenic for mosquito larvae. J Invertebr Pathol 1990, 55:130-132.

44. Daoust RA, Ward MG, Roberts DW: Effect of formulation on the virulence of Metarhizium anisopliae conidia against mosquito larvae. J Invertebr Pathol 1982, 40:228-236.

45. Gunnarsson SG, Lackie AM: Hemocytic aggregation in Schistocerca gregaria and Periplaneta americana as a response to injected substances of microbial origin. J Invertebr Pathol 1985, 46:312-319.

46. Hegedus DD, Khachatourians GG: The impact of biotechnology on hyphomycetous fungal insect biocontrol agents. Biotech Adv 1995, 13:455-490.

47. Mulla MS, Thavara U, Tawatsin A, Chomposri J, Su T: Emergence of resistance and resistance management in field populations of tropical Culex quinquefasciatus to the microbial control agent Bacillus sphaericus. J Am Mosq Control Assoc 2003, 19:39-46.

48. Zimmermann G: Review on safety of the entomopathogenic fungus Metarhizium anisopliae. Biocontrol Sci Techn 2007, 17:879-920.

49. Zimmermann G: Review on safety of the entomopathogenic fung Beauveria bassiana and Beauveria brongniartii. Biocontrol Sci Techn 2007, 17:553-596.

50. Hunt TR, Moore D, Higgins PM, Prior C: Effect of sunscreens, irradiance and resting periods on the germination of Metarhizium flavoviride conidia. Entomophaga 1994, 39:313-322.

51. Morley-Davies J, Moore D, Prior C: Screening of Metarhizium and Beauveria spp. conidia with exposure to simulated sunlight and a range of temperatures. Mycol Res 1996, 100:31-38.

52. Lord JC, Roberts DW: Host age as a determinant of infection rates with the mosquito pathogen Lagenidium giganteum (Oomycetes: Lagenidiales). J Invertebr Pathol 1987, 50:70-71.

53. Meylaers K, Freitak D, Schoofs L: Immunocompetence of Galleria mellonella: sex- and stage-specific differences and the physiological cost of mounting an immune response during metamorphosis. J Insect Physiol 2007, 53:146-156.

54. Tsuji Y, Nakajima Y, Homma K-i, Natori S: Antibacterial activity of a novel 26-kDa serine protease in the yellow body of Sarcophaga peregrina (flesh fly) pupae. FEBS Letters 1998, 425:131-133.

55. Kokoska L, Janovska D, Rada V, Nepovim A, Vanek T: In vitro antibacterial activity of four Leuzea species. Pharmaceut Biol 2005, 43:8-11.

56. Bede JC, Tobe SS: Activity of insect juvenile hormone III: seed germination and seedling growth studies. Chemoecology 2000, 10:89-97.

57. Pelizza SA, Oacute, Pez Lastra CC, Becnel JJ, Bisaro V, Garc, lacute, A JJ: Biotic and Abiotic Factors Affecting Leptolegnia chapmanii Infection in Aedes aegypti. J Am Mosa Control Assoc 2007, 23:177-181.

58. Genthner FJ, Chancy CA, Couch JA, Foss SS, Middaugh DP, George SE, Warren MA, Bantle JA: Toxicity and pathogenicity testing of the insect pest control fungus Metarhizium anisopliae. Arch Environ Contam Toxicol 1998, 35:317-324.

59. Genthner FJ, Foss SS, Fisher WS: Testing of the insect pest-control fungus Beauveria bassiana in grass shrimp Palaemonetes pugio. Dis Aquat Org 1994, 20:49-57.

60. Genthner FJ, Middaugh DP: Non target testing of an insect control fungus - effects of Metarhizium anisopliae on developing embryos of the inland silverside fish Menidia beryllina. Dis Aquat Org 1995, 22:163-171.

61. Henke MO, de Hoog GS, Gross U, Zimmerman G, Kraemer D, Weig M: Human deep tissue infection with an entomopathogenic Beauveria species. J Clin Microbiol 2002, 40:2698-2702.

doi:10.1186/1475-2875-9-22

Cite this article as: Bukhari et al:: Factors affecting fungus-induced larval mortality in Anopheles gambiae and Anopheles stephensi. Malaria Journal 2010 9:22. 